\title{
Analysis of the Omnium-G Receiver
}

Mark Bohn
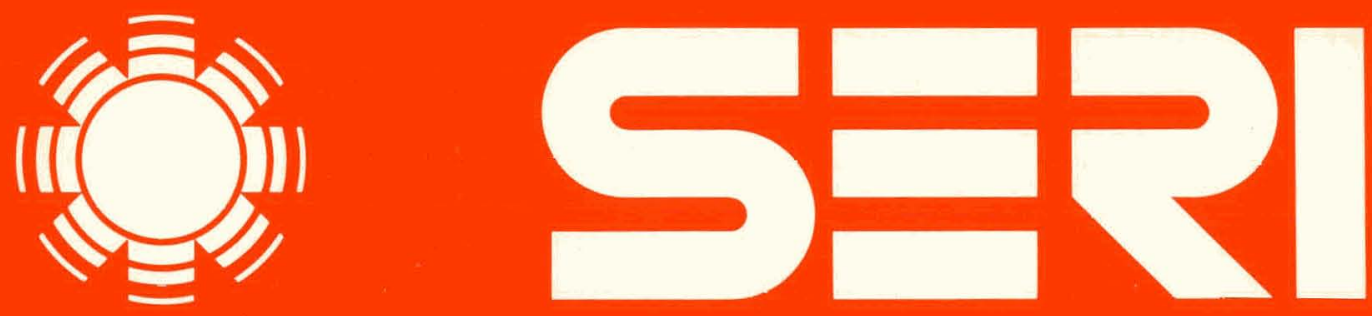

Solar Energy Research Institute A Division of Midwest Research Institute

1617 Cole Boulevard

Golden, Colorado 80401

Operated for the

U.S. Department of Energy under Contract No. EG-77-C-01-4042 


\section{DISCLAIMER}

This report was prepared as an account of work sponsored by an agency of the United States Government. Neither the United States Government nor any agency Thereof, nor any of their employees, makes any warranty, express or implied, or assumes any legal liability or responsibility for the accuracy, completeness, or usefulness of any information, apparatus, product, or process disclosed, or represents that its use would not infringe privately owned rights. Reference herein to any specific commercial product, process, or service by trade name, trademark, manufacturer, or otherwise does not necessarily constitute or imply its endorsement, recommendation, or favoring by the United States Government or any agency thereof. The views and opinions of authors expressed herein do not necessarily state or reflect those of the United States Government or any agency thereof. 


\section{DISCLAIMER}

Portions of this document may be illegible in electronic image products. Images are produced from the best available original document. 
Printed in the United States of America Available from:

National Technical Information Service

U.S. Department of Commerce

5285 Port Royal Road

Springfield, VA 22161

Price:

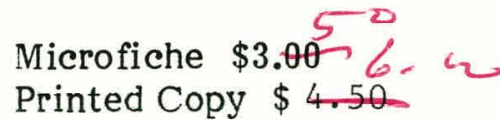

NOTICE

This report was prepared as an account of work sponsored by the United States Government. Neither the United States nor the United States Department of Energy, nor any of their employees, nor any of their contractors, subcontractors, or their employees, makes any warranty, express or implied, or assumes any legal liability or responsibility for the accuracy, completeness or usefulness of any information, apparatus, product or process disclosed, or represents that its use would not infringe privately owned rights. 
SER I /TR-631-387

UC CATEGORY: UC-62

ANALYSIS OF THE OMNIUM-G RECEIVER

MARK BOHN

MARCH 1980

PREPARED UNDER TASK NO. 3457.11

\section{Solar Energy Research Institute}

1536 Cole Boulevard

Golden, Colorado 80401

A Division of Midwest Research Institute

Prepared for the

U.S. Department of Energy

Contract No. EG.77.C.01.4042 


\section{THIS PAGE}

\section{WAS INTENTIONALLY \\ LEFT BLANK}


TR -387

FOREWORD

This report documents work done on task 3457.11 (Receiver R\&D) in the Solar Thermal Research Branch of the Solar Energy. Research Institute.

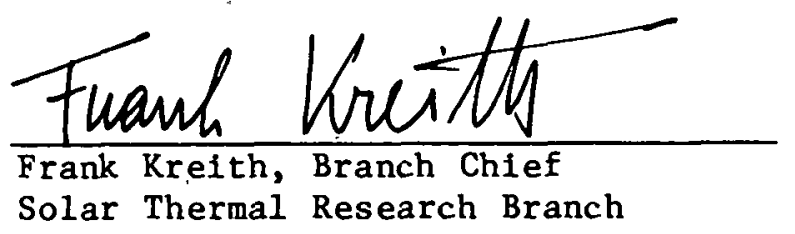

Approved for:

SOLAR ENERGY RESEARCH INSTITUTE

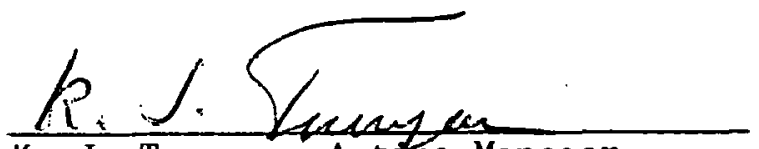

K. J. Touryan, Act, th g Manager

Solar Thermal, OKféan, and Wind Division

111 
THIS PAGE

\section{WAS INTENTIONALLY LEFT BLANK}




\section{SURMARY}

A thermal analysis of the Omnium-G receiver is presented and the technique is shown to be generally applicable to solar thermal receivers utilizing a directly heated thermal mass. The thermal loss coefficient, including reradiation losses, is calculated and shown to agree quite well with the experimentally measured thermal loss coefficterit.

The rate of heat transfer to the working fluid is also analyzed and the analysis is used to show that the Omnium-G recelver is well matched to the water/ steam working fluid because the steam outlet temperature is almost the same as the receiver temperature.

Finally, a general procedure for calculating receiver performance is presented; with this procedure, the energy delivery to any working fluid, the delivered temperature of the working fluid, and the pressure drop through the recelver can be determined. An example of the calculation is also presented. 


\section{THIS PAGE}

\section{WAS INTENTIONALLY \\ LEFT BLANK}


TABLE OF CONTENTS

Page

Nomenclature........................................ $x i$

1.0 Introduction $\ldots \ldots \ldots \ldots \ldots \ldots \ldots \ldots \ldots \ldots \ldots \ldots \ldots \ldots \ldots \ldots \ldots \ldots \ldots \ldots \ldots \ldots \ldots \ldots$

2.0 Receiver Heat Loss Analysis............................ 3

3.0 Heat Transfer to the Working Fluid....................... ll

4.0 General Procedure for Calculating Receiver Performance.......... 13

$5.0 \quad$ References........................................... 15

Appendix............................................ A-1

A.1 Receiver Dimensions and Material Properties............... A-1

A.2 Calculation of Thermal Resistance......................... A-1

A.3 Thermo-optical Performance of an Isothermal Cavity Receiver.... A-2

A.4 Sample Performance Calculation: 1500 PSIA, 1100 F Steam....... A-4 
THIS PAGE

\section{WAS INTENTIONALLY \\ LEFT BLANK}


SEP

$\mathrm{TR}-387$

LIST OF FIGURES

Page

$2-1 \quad$ Receiver........................................... 4

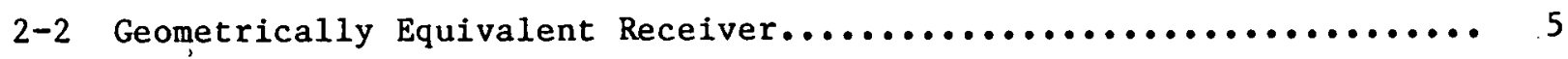

2-3 Equivalent Thermal Network.......................... 7

LIST OF TABLES

A-1 Heat Transfer to Working Fluid: Inlet to Saturation............ A-5

A-2 Heat Transfer to Working Fluid: Saturation to Outlet............ A-6 


\section{THIS PAGE \\ WAS INTENTIONALLY \\ LEFT BLANK}




\section{NOMENCLATURE}

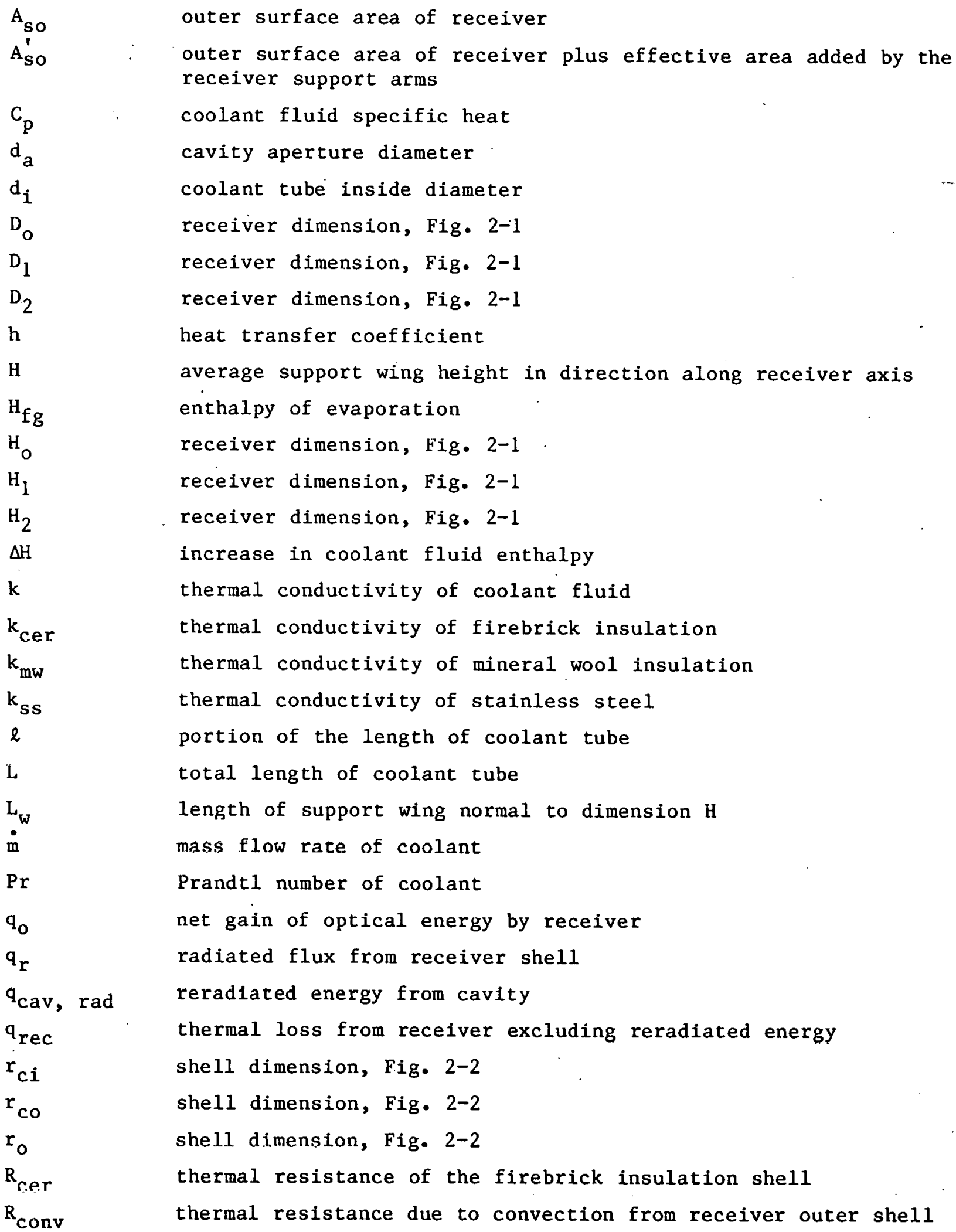




\section{NOMENCLATURE (concluded)}

$\mathrm{R}_{\mathrm{mw}}$

$\mathrm{R}_{\text {rad }}$

$\mathrm{R}_{\mathrm{R}}$

$\mathrm{R}_{\text {wing }}$

$\operatorname{Re}$

$\mathrm{T}_{\mathrm{f}}$

$\mathrm{T}_{\mathrm{R}}$

$T_{\text {s }}$

$\mathrm{T}_{\infty}$

$\mathrm{U}$

w

$\varepsilon_{\ell}$

$\varepsilon_{\mathrm{s}}$

$\varepsilon_{\text {sS }}$

$\mu$

$\sigma$

thermal resistance of the mineral wool insulation shel1

thermal resistance due to radiation from receiver outer shell

net thermal resistance from thermal mass to ambient (excluding cavity reradiation)

thermal resistance of the receiver support wing

Reynolds number

working fluid temperature

receiver cavity temperature

temperature of the receiver outer shell

ambient temperature

ambient wind speed

thickness of support wing material

long wave emittance of the cavity material

short wave emittance of the cavity material

long wave emittance of the receiver outer shell

viscosity of coolant fluid

Stefan-Boltzman constant 


\section{SECTION 1.0}

\section{INTRODUCTION}

The performance of the Omnium-G* (0.G.) solar power plant was described previously (Bohn 1979) in terms of the amount of thermal energy the concentrator/receiver could deliver to a heat engine. Electrical output was given as a function of beam insolation and heat engine efficiency. The 0.G. receiver was described briefly and a simple experimental technique for measuring the thermal loss coefficient of the receiver and the optical efficiency of the concentrator/receiver was presented. That method did not require a detailed thermal analysis of the receiver. The analysis presented in this report allows one to understand the relative importance of the various mechanisms of heat loss from the receiver.

Analysis of the heat transfer from the receiver to the working fluid yields not only the quantity of energy delivered to the fluid, but also the quality of the energy (i.e., the temperature at which the fluid is delivered). Performances of different working fluids may then be assessed. The usefulness of a receiver analysis of this type may appear limited because it is applicable only to the O.G. receiver. However, the analysis presented here applies to a class of receivers--those utilizing a directly heated thermal mass as a heat flux buffer. The analysis may seem unnecessary since computer programs developed specifically for solar thermal receiver analysis are available (Lansing). Receivers of this type, however, are amenable to a greatly simplified analysis procedure, as described in this report. In addition, Lansing's computer program is not yet sufficiently developed to be a useful design tool.

In the following sections, the analysis of the O.G. receiver thermal loss is presented and the results are compared to the experimental results given in SERI/TP-34-169 (Bohn 1979). Various mechanisms of heat loss from the receiver are compared and the receiver design is discussed. Analysis of the heat transfer to the working fluid follows and, finally, a method for determining receiver performance over a wide range of operating conditions is presented.

*Omnium-G is a company in Anaheim, Calif., that manufactures and sells pointfocus parabolic solar concentrators and related equipment, including solar thermal receivers. 


\section{SEP1.}




\section{SECTION 2.0}

\section{RECBIVER HEAT LOSS ANALYSIS}

A drawing of the 0.G. recelver is shown in Fig. 2-1. This is the version of the receiver that was tested at SERI in early 1979 and for which results were given by Bohn. Several engineering modifications have been made to the receiver since then, but these do not affect the basis of this analysis. Furthermore, it is useful to compare the test results with this analysis because a consistent receiver must be used.

As shown in Fig. '2-1, the 0.G. receiver is based upon a thermal mass of aluminum; in this case, $33.7 \mathrm{~kg}$. The purpose of this mass is to give both temporal and spatial smoothing to the heat flux impinging on the cavity surface. This is useful because it insures smooth operation of the entire system and minimizes the chance of burnout of the coolant tubes. These features are essential for receivers used to heat the endothermically reacting fluids currently under study at SERI. As described in Bohn 1979, the 0.G. receiver was operated with the aluminum mass in the molten state as recommended by Omnium-G. Results of that experiment showed that corrosion of the stainless steel cooling coils by the molten aluminum leads to very rapid failure. Therefore, operation of the receiver above the melting temperature of aluminum is no longer recommended.

The thermal mass has two disadvantages. The first disadvantage is the extra mass that the concentrator frame must support at the focus (compared to the exposed cooling tube configuration). This has impact on the tracking controls and on the structural strength of the concentrator framework. The second disadvantage is the temperature gradient across the thermal mass--a loss of second-law efficiency. However, if the thermal mass has a high conductivity, the temperature drop across the mass to the working fluid is very small relative to the absolute operating temperature of the mass.

Thermal analysis of such a receiver is greatly simplified because the thermal mass may be considered isothermal. Therefore, receiver losses are due to both conduction through various thermal resistances to the receiver outer shell and reradiation by the 1sothermal cavity. The method used to analyze the 0.G. receiver is to find the thermal resistance circuit for the conduction path and to compute reradiation from the cavity. Since the thermal mass is surrounded by layers of insulation, the receiver is considered as a series of concentric spherical shells, as shown in Fig. 2-2. The radius of each shell is such that the surface area is equal to that of the corresponding layer in the actual receiver. For example, the outer shell radius is $r_{0}$, where

$$
4 \pi\left(\mathrm{r}_{\mathrm{o}}\right)^{2}=\frac{1}{4} \pi\left(\mathrm{D}_{\mathrm{o}}\right)^{2}\left(2-\frac{\mathrm{d}_{\mathrm{a}}^{2}}{\mathrm{D}_{\mathrm{o}}^{2}}\right)+\pi \mathrm{D}_{\mathrm{o}} \mathrm{H}_{\mathrm{o}}=\mathrm{A}_{\text {so }} \cdot
$$




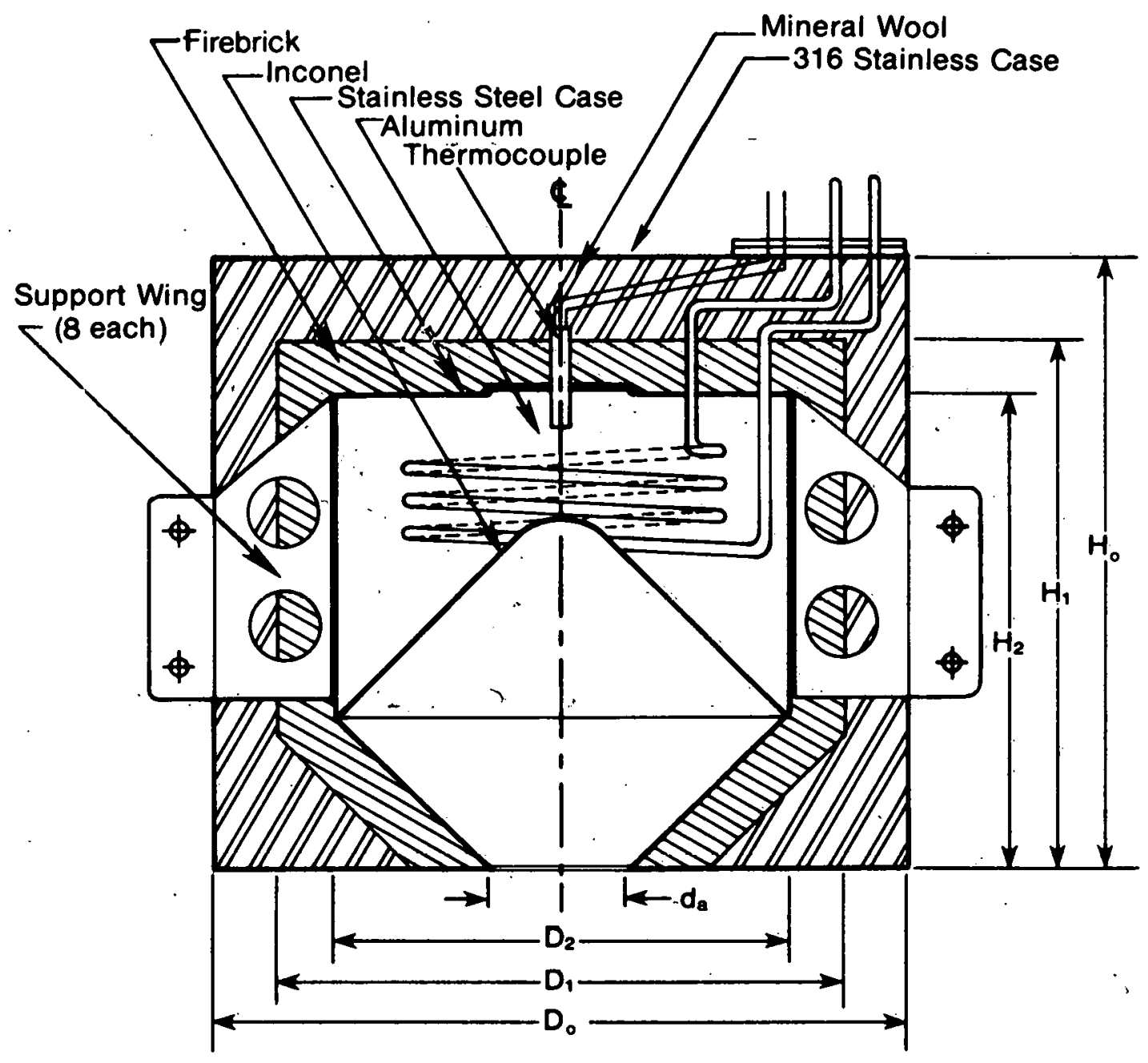

Figure 2-1. Recelver 


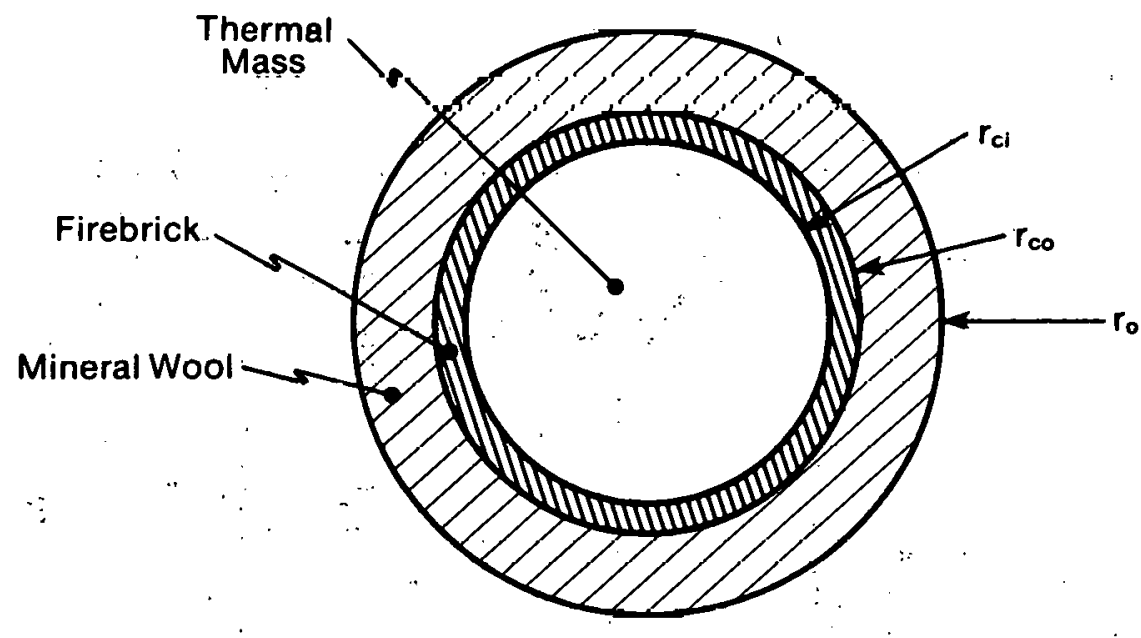

Figure 2-2. Geometrically Equivalent Receiver 
The next shell of radius $r_{\text {co }}$ corresponds to the Inner surface of the mineral wool insulation:

$$
4 \pi\left(r_{c o}\right)^{2}=\frac{1}{4} \pi\left(D_{1}\right)^{2}+\pi D_{1} H_{1}
$$

The third shell of radius $r_{c i}$ corresponds to the ceramic insulation inner surface:

$$
4 \pi\left(r_{c i}\right)^{2}=\frac{1}{4} \pi\left(D_{2}\right)^{2}+\pi D_{2} H_{2}
$$

Numerical values are given in the Appendix.

The thermal resistance $R$ from a spherical shell of radius $r_{1}$ to a concentric spherical shell of radius $r_{2}$ with thermal conductivity $k$ between $r_{1}$ and $r_{2}$ is

$$
R=\frac{r_{1}^{-1}-r_{2}^{-1}}{4 \pi k}
$$

The thermal network is shown in Fig. 2-3. Conduction from the thermal mass to the recelver outer shell follows two parallel paths: through the ceramic inner insulation in series with the mineral wool and through the eight stainless steel support wings. Loss from the recelver outer shell-is by convection and radiation to the ambient. Cavity reradiation is dependent only on cavity temperature and geometry.

Note that the receiver outer shell is given as one node at temperature $\mathrm{T}_{s}{ }^{*}$ This is not strictly correct since one would expect thermal gradients in the shell (e.g., the temperature at the junction of a support wing and the shell might be higher than at other points on the she11). However, since the shell has much higher conductivity than the insulation below 1t, thermal gradients in the shell should be minimized. Surface temperatures were measured during testing of the $0 . G$. recelver. These measurements support the use of a single node representing the recelver outer shell. For a recelver operating at $\mathrm{T}_{\mathrm{R}}=660 \mathrm{C}$ and $\mathrm{U}=1.9 \mathrm{~m} / \mathrm{s}$, the temperature of the recelver shell was measured at five locations. The largest variation between any two of these locations was an $18 \mathrm{C}$ difference between the point where the support wing joins the shell and the point on the shell one-half the distance between two points which join the support wings. 

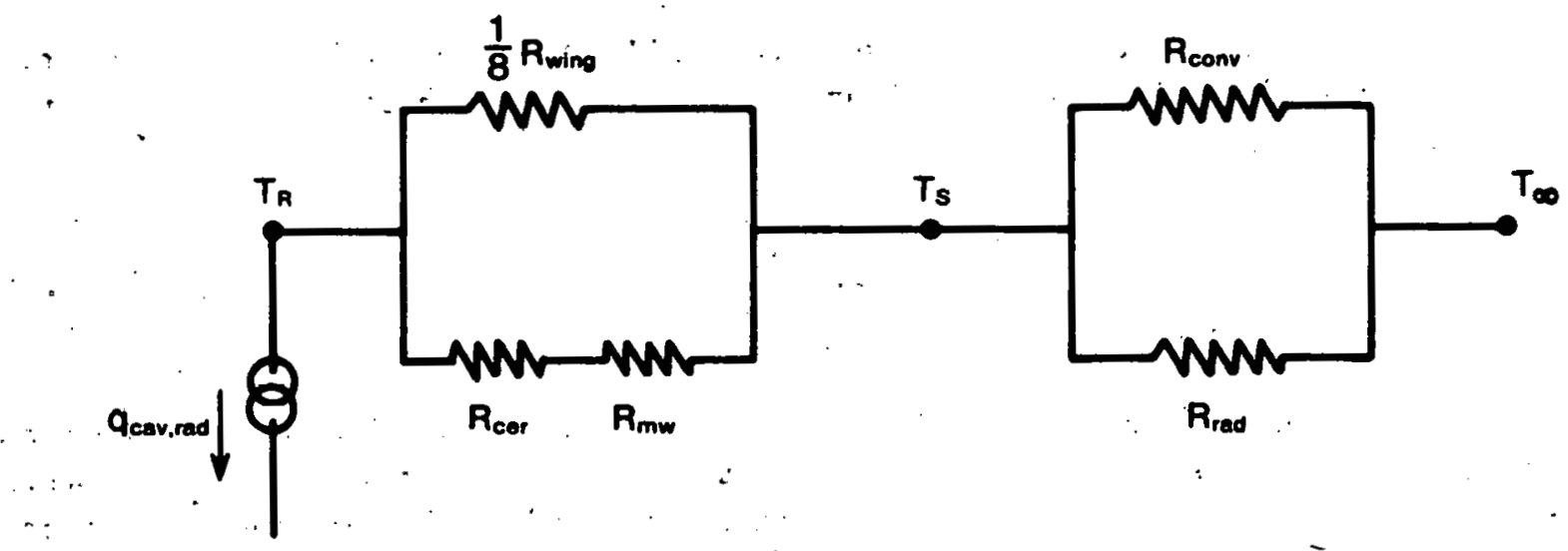

Figuire 2-3. Equivalent Thermal Network 
Thermal resistance of the support wings, mineral wool, and ceramic insulation is, as computed in the Appendix,

$$
\begin{aligned}
\frac{1}{8} R_{\text {wing }} & =1.39 \mathrm{C} / \mathrm{W} \\
R_{\text {cer }} & =0.31 \mathrm{C} / \mathrm{W} \\
R_{\mathrm{mW}} & =1.08 \mathrm{C} / \mathrm{W}
\end{aligned},
$$

Convection thermal resistance was calculated by assuming the receiver is a sphere of radius $r_{0}$ immersed in a flow of velocity $U$ (wind velocity, $m / s$ ). According to McAdams (1954), the Nusselt-Reynolds number correlation is

$$
\begin{aligned}
& N u=0.37 \operatorname{Re}^{0.6}, \\
& 17<\operatorname{Re}<70,000,
\end{aligned}
$$

where the Reynolds number is based on the sphere diameter. Using the properties of air at a film temperature of $27 \mathrm{C}$, we find: -

$$
\begin{aligned}
\mathrm{R}_{\text {conv }}=\left(\mathrm{hA}_{\text {so }}^{\prime}\right)^{-1} & =0.086 \mathrm{U}^{-0.6} \mathrm{c} / \mathrm{W} \\
& =0.059 \mathrm{c} / \mathrm{W} \propto 1.9 \mathrm{~m} / \mathrm{s} .
\end{aligned}
$$

The total surface area $A_{\text {so }}^{\prime}$ was calculated by assuming that the four receiver support arms act as infinitely long fins. Fin effectiveness was calculated for straight aluminum fins of $1.2 \mathrm{~mm}$ thickness and surface area $0.239 \mathrm{~m}^{2}$ per meter of fin length which is the thickness and the surface area per unit length of the tubular aluminum support arms. This calculation shows that the support arms add about $7 \%$ to the receiver surface area $A_{\text {so }}$.

Radiation loss from the receiver surface area may be written as

$$
q_{r}=\varepsilon_{s s} A_{s o} \sigma\left(T_{s}^{4}-T_{\infty}^{4}\right)
$$

The corresponding thermal resistance is

$$
1 / R_{r a d}=\varepsilon_{s s} A_{s o} \sigma\left(T_{s}^{2}+T_{\infty}^{2}\right)\left(T_{s}+T_{\infty}\right) .
$$


A mean value of $R_{\text {rad }}$ for the expected range of ambient and surface temperatures is

$$
R_{\text {rad }}=0.49 \mathrm{C} / \mathrm{W}
$$

The equivalent thermal resistance from the thermal mass to ambient is

$$
\begin{aligned}
R_{R} & =\frac{\frac{1}{8} R_{\text {wing }}\left(R_{c e r}+R_{\text {mw }}\right)}{\frac{1}{8} R_{\text {wing }}+R_{\text {cer }}+R_{\text {mw }}}+\frac{R_{\text {rad }} R_{\text {conv }}}{R_{\text {rad }}+R_{\text {conv }}} \\
& =0.70+0.05=0.75 \quad \text { C } / \text { W } Q U=1.9 \mathrm{~m} / \mathrm{s}
\end{aligned}
$$

Cavity reradiation is shown in the Appendix to be blackbody radiation from the receiver aperture. Therefore, we have an additional loss

$$
q_{c a v, ~} \operatorname{rad}=\frac{1}{4} \pi\left(d_{a}\right)^{2} \sigma\left(T_{R}\right)^{4} .
$$

The total thermal loss from the receiver may be written as

$$
q_{\text {réc }}=\frac{T_{R}-T_{\infty}}{K_{R}}+\frac{1}{1} \pi\left(d_{a}\right)^{2} \sigma\left(T_{R}\right)^{4} .
$$

As reported by Bohn (1979), the thermal loss from the 0.G. receiver was weasured for the conditions

$$
\begin{aligned}
& \mathrm{T}_{\mathrm{R}}=660 \mathrm{C}, \\
& \mathrm{T}_{\infty}=4 \mathrm{C}, \\
& \mathrm{U}=1.9 \mathrm{~m} / \mathrm{s} ;
\end{aligned}
$$

and measured loss was

$$
4_{\mathrm{rec}}=1412 \mathrm{~W}
$$

Equatiun 2-13 predicts

$$
q_{\text {rec }}=1223 \mathrm{~W}
$$

One mode of heat loss from the receiver, the loss due to convection from the receiver aperture, was not included in this analysis. Although some attempts have been made recently [12] to measure such losses from cavity receivers, not 
enough information exists to allow the results to be extrapolated to the 0.G. receiver. The results do suggest that such losses are not negligible and could very likely account for the discrepancy between measured and computed receiver thermal loss.

From Fig. 2-3 and the calculation of the various thermal resistances, we see that the cavity reradiation is about one-fourth of the total receiver loss. The remainder is due to conduction from the thermal mass through the two insulation layers, and from the support wings to the receiver shell. The energy is then convected and radiated from the shell.

The internal conduction paths are balanced:

$$
\begin{aligned}
& \frac{1}{8} R_{\text {wing }}=1.39 \mathrm{C} / \mathrm{W}, \\
& \mathrm{R}_{\text {cer }}+\mathrm{R}_{\mathrm{mw}}=1.39 \mathrm{C} / \mathrm{W} .
\end{aligned}
$$

Since these two resistances are in parallel, it would not be a good design if one resistance differed greatly from the other.

Thermal resistance from the receiver shell to ambient is the parallel combination of $R_{\text {rad }}$ and $R_{\text {conv }}$. Due to the low temperature of the receiver shell, radiation plays a minor role in dissipating the energy to ambient from the she11 (compare Eqs. 2-7 and 2-10).

The total thermal resistance of the network depends only weakly upon the resistance from the receiver shell to ambient. This means that the thermal mass has been insulated sufficiently such that the receiver loss depends little on ambient wind.

Further work to reduce $\mathrm{q}_{\text {rec }}$ does not seem necessary because of receiver size constraints (which limit the amount of insulation) and the operating temperature (which determines the type of insulation), and because the total receiver loss is only about $5 \%$ of the gross energy input to the concentrator aperture (Bohn 1979). 
SECTION 3.0

\section{HEAT TRANSFER TO THE WORKING FLUID}

The assumption of an isothermal recelver mass simplifies calculation of heat transfer to the working fluid being pumped through the mass. Given fluid properties and mass flow rate, the heat transfer coefficient $h$ may be calculated from appropriate correlations. The increase in enthalpy of the fluld $\Delta \mathrm{H}$ over a length of the coolant tube $\ell$, for which fluid properties are relatively constant, can then be calculated from

$$
\dot{\mathrm{m} \Delta \mathrm{H}}=\mathrm{h} \pi \mathrm{d}_{\mathrm{i}} \ell\left(\mathrm{T}_{\mathrm{R}}-\mathrm{T}_{\mathrm{f}}\right),
$$

and the corresponding increase in fluid temperature over that length $\ell$ is

$$
\Delta \mathrm{T}_{\mathrm{f}}=\Delta \mathrm{H} / \mathrm{C}_{\mathrm{p}}
$$

For very high flow rates, $\mathrm{T}_{\mathrm{f}}$ will increase slightly so fluid propertles.are essentially constant at the inlet value. In this case $\ell=\dot{L}$, i.e., the entire tube length.

To generate high fluid temperatures, the mass flow must be reduced. Since the fluid properties may vary significantly (or, as in the case of steam generation, a phase change may occur), it is necessary to "step" through the coolant tube in steps short enough to allow the fluid properties to be considered constant.

An example of such a calculation is presented in the Appendix. This calculation is performed for water coolant giving superheated steam at the receiver outlet, as consistent with the O.G. recelver design. The result is that the steam temperature at the receiver outlet is essentially $T_{R}$ because the coolant tube is long relative to the heat transfer coefficient of the inside of the coolant tube (i.e., the recelver has high heat exchanger effectiveness). Th1s rcsult also simplifies the receiver calculation. The steam uutlet cemperature is $T_{R}$ and the overall increase of steam enthalpy must equal the net optical energy focused into the cavity minus the thermal loss:

$$
\mathrm{q}_{\mathrm{o}}-\mathrm{q}_{\mathrm{rec}}=\dot{\mathrm{m} \Delta \mathrm{H}}
$$

The net optical energy focused into the cavity is a function of concentrator quality, cavity geometry, and cavity materials (see Appendix). It is independent of $T_{R}$. Therefore, $1 f$ both the insolation and the desired steam outlet 
temperature $T_{R}$ are specified, the receiver thermal loss is determined and the water flow rate is known.

The pressure drop through the receiver cooling tube may be calculated by using an appropriate friction-factor Reynolds-number correlation and, if necessary, by stepping through the recelver to get the total pressure drop. In the case of steam, this calculation may be performed after the temperature distribution through the coolant tube is determined (because the mass flow rate for steam is so low that the frictional pressure drop is very small and the effect on the fluid thermal properties is negligible). For very high flow rates, such as may occur during measurements of receiver optical efficiency (where $T_{R}$ is held to a minimum to reduce thermal losses), the pressure drop is significant and determines the flow rate. Under these conditions, steam is not produced (the water temperature changes only slightly) and the thermal properties are not'a strong function of pressure. 
SECTION 4 -10

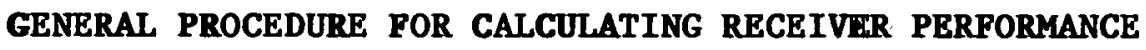

For working fluids other than water or water/steam and under different operating conditions, the calculation is similar to that described in Section 3.0 .

With the concentrator/receiver optical properties and insolation given, net optical energy gain is determined. Next, it is assumed that the desired ourler fluid temperature $T_{R}$ is known (therefore, the receiver thermal loss is also knowin). 'lhe' fluid flow rate is salsulated with Fiq $3-3$ and the rluld propertles. Next, it must be determined whether the assumption of the outlet fluid temperature as $T_{R}$ is correct. With the calculated flow rate and fluid properties as a function of temperature, the receiver cooling tube is stepped through (Eqs. 3-1 and 3-2) and the fluid outlet temperature is determined. If the outlet fluid temperature is $T_{R}$, the pressure drop may then be calculated. If the fluid temperature is significantly less than $T_{R}$, Eq. 3-3 is not satisfied. In this case, the flow rate must be adjusted to satisfy Eq. 3-3 and the receiver must be stepped through again to determine the outlet fluid temperature. Several iterations may be required.

There will be two cases when the outlet fluid temperature is not $T_{R}$. When a very large flow rate is used to keep the receiver as cool as possible (such as during optical efficiency measurements), the fluid temperatures (and, therefore, fluid properties) will change only slightly, so the solution of Eqs. 3-1 and 3-2 will require one step. The occond case will uccur at high recelver temperatures when the wnrking fluid ic poorly matched tu lle receiver. In this case the desired outlet fluid temperature can be achieved only by operating the recelver at a significantly higher temperature. The efficiency is low, therefore, and a different working fluid should be chosen. 
SERI 


\section{SECTION 5.0}

\section{REPERENCES}

1. Baumeister, T., ed. 1967. Standard Handbook for Mechanical Engineers. New York: McGraw-Hill.

2. Bohn, M. 1979. "Performance Characteristics of a Commercially Available Point-Focus Solar Power System." Proceedings of the 1979 Heat Transfer

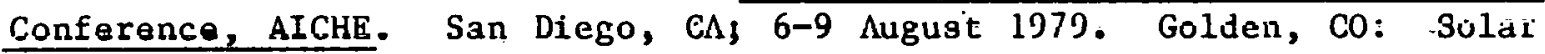
Energy Research Institute; SERI/TP-34-169.

3. Davis, E. J.; David, M. M. 1964. "Two Phase Gas-Liquid Convection Heat Transfer." I\&EC Fundamentals. Vol. 3 (no. 2): p. 111 .

4. Griffith, P. "The Correlation of Nucleate Boiling Burnout Data." ASME paper 57-HT-21.

5. Kaminski, D. A., ed. 1977. General Electric Data Book - Heat Transfer. Secs. 513, 514. July.

6. Keenan, J. H.; et al. 1969. Steam Tables. New York: John Wiley and Sons.

7. Lansing, F. L. HEAP: Heat Energy: Analysis Program. DOE/JPL-1060-13.

8. McAdams, W. H. 1954. Heat Transmission. 3rd ed. New York: McGrawHill.

9. Rohsenow, W., ed. 1973. Handbook of Heat Transfer. New York: McGrawHill.

10. Toulouk1an, Y. S., ed. 1970. Thermal Radiative Properties, Metallir. Filements and Alloys. New York: Plenum Press.

11. Colburn, A. P. 1933. "A Method of Correlating Forced Convertinn Heat Transfer Data and a Comparison with Fluid Friction." Trans. AICHE, Vol. 29, p. 174 .

12. Saydah, A. R.; Koeniy, A. A.; Lambert, R. H.; and Kugath, D. A. 1979. "f'inal Report on Test of STĒP, Shenandoah Parabolic Dish Solar Collector Quadrant Facility." Philadelphia, PA: General Electric Company, Space Division. December. 


\section{SE키누}




\section{APPENDIX}

\section{A.1 RECEIVER DIMENSIONS AND MATERIAL PROPERTIES}

$$
\begin{aligned}
\mathrm{D}_{0} & =50.8(\mathrm{~cm}) \\
\mathrm{D}_{1} & =40.0 \\
\mathrm{D}_{2} & =32.4 \\
\mathrm{H}_{0} & =45.6 \\
\mathrm{H}_{1} & =39.2 \\
\mathrm{H}_{2} & =35.2 \\
\mathrm{~d}_{\mathrm{a}} & =10.0 \\
\mathrm{~L} & =244.0 \\
\mathrm{~d}_{i} & =0.3
\end{aligned}
$$

\begin{tabular}{|c|c|c|c|c|c|c|}
\hline$\varepsilon_{\text {SS }}$ & 0.28 & & & Ba uneister & 1967 & $(24 c)$ \\
\hline$k_{c e r}$ & 0.187 & $\mathrm{~W} / \mathrm{m}$ & $\mathrm{C}$ & Mfg. data & & $\left(\begin{array}{ll}560 & C\end{array}\right)$ \\
\hline & 0.086 & $\mathrm{~W} / \mathrm{m}$ & $\mathrm{C}$ & Ba imeister & 1967 & $(280 \mathrm{C})$ \\
\hline$k_{s 8}$ & 21.6 & $\mathrm{~W} / \mathrm{m}$ & C & Baumeister & 1967 & $(560 r)$ \\
\hline 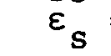 & 0.88 & & & Touloukian & 1970 & \\
\hline$\varepsilon_{\ell}$ & 0.85 & & & Touloukian & 1970 & \\
\hline
\end{tabular}

Source

\section{A.2 CALCULATION OF THERMAL RESIS'IANCE}

From Eq. 2-1:

$$
\begin{aligned}
& r_{0}=0.30 \mathrm{~m}, \\
& r_{c o}=0.22 \mathrm{~m}, \\
& r_{c i}=0.19 \mathrm{~m} .
\end{aligned}
$$

From Eq. 2-4:

$$
\begin{aligned}
& \mathrm{R}_{\mathrm{mw}}=\frac{1 / \mathrm{r}_{\mathrm{co}}-1 / \mathrm{r}_{\mathrm{o}}}{4 \pi \mathrm{k}_{\mathrm{mw}}}=1.08 \mathrm{c} / \mathrm{W}, \\
& \mathrm{R}_{\text {cer }}=\frac{1 / \mathrm{r}_{\mathrm{ci}}-1 / \mathrm{r}_{\mathrm{co}}}{4 \pi \mathrm{k}_{\text {cer }}}=0.31 \mathrm{C} / \mathrm{W} .
\end{aligned}
$$


The thermal resistance of the support wings was calculated by a method suggested in Rohsenow (1973). This method essentially assumes that the thermal conductivity of the wing material is decreased by the same fraction that the area of the wing is decreased due to the holes (Fig. 2-1). This fraction is $13 \%$. The' wing is then assumed to be rectangular with a height $H$ (dimension along receiver axis) equal to the average of the two sides shown in Fig. 2-1 $(22.2 \mathrm{~cm}$ and $15.2 \mathrm{~cm})$. The dimension $\mathrm{L}_{\mathrm{w}}$ normal to the height is $12.7 \mathrm{~cm}$ and the wings are made of 316 stainless steel plate, $0.32 \mathrm{~cm}$ thick. The wing thermal resistance is

$$
\begin{aligned}
\mathrm{R}_{\text {wing }} & =\frac{\mathrm{L}_{\mathrm{w}}}{\mathrm{k}_{\text {SS }} \mathrm{wH}}(1.13) \\
& =11.1 \mathrm{C} / \mathrm{W} .
\end{aligned}
$$

\section{A. 3 THERMO-OPTICAL PERFORMANCE OF AN ISOTHERMAL CAVITY RECEIVER}

Consider a cavity receiver with a cavity surface at uniform temperature $T$, surface area $A_{1}$, and cavity aperture area $A_{2}$. Assume that the radiation exchange is diffuse and exists in two bands, and that the cavity surface emittance in these two bands is

and

$$
\varepsilon_{\ell}=\text { long wave emittance, }
$$

$$
\varepsilon_{\mathbf{s}}=\text { short wave emittance. }
$$

Suppose the solar energy crossing $A_{2}$ into the cavity is $Q_{s o 1^{*}}$. Define $q_{0}^{\prime}$ to be the flux leaving the cavity surface (averaged over $A_{1}$ ), which is the sum of a long wave component and a short wave component:

$$
q_{o}^{\prime}=q_{o \ell}+q_{o s}
$$

Similarly, define $\mathrm{q}_{i}$ to be the flux impinging upon the cavity surface (averaged over $\left.A_{1}\right)$ :

$$
u_{i}-u_{i \ell}+q_{i s}
$$

Then

$$
q_{1 s}=\frac{Q_{\text {sol }}}{A_{1}}+q_{o s} F_{11} \text {, }
$$


and

and

$$
\begin{gathered}
q_{o s}=\left(1-\varepsilon_{s}\right) q_{1 s}, \\
\therefore q_{o s}=\left[\frac{1-\varepsilon_{s}}{1-\left(1-\varepsilon_{s}\right) F_{11}}\right] \frac{Q_{s o 1}}{A_{1}} ;
\end{gathered}
$$

$$
\begin{gathered}
q_{1 \ell}=q_{o \ell} F_{1 l}, \\
\ddot{y}_{o \ell}=\varepsilon_{\ell} T^{4}+\left(1-\varepsilon_{\ell}\right) q_{1 \ell}, \\
\therefore \quad q_{o \ell}=\frac{\varepsilon_{\ell} \sigma T^{4}}{1-\left(1-\varepsilon_{\ell}\right) F_{11}} .
\end{gathered}
$$

The cavity-to-cavity view factor $F_{11}$ may be calculated from the reciprocity relation

$$
A_{1} F_{12}=A_{2} F_{21}
$$

The aperture sees only the cavity, $F_{21}=1$, and therefore

$$
F_{12}=A_{2} / A_{1}
$$

or

$$
F_{11}=1-A_{2} / A_{1}
$$

Long wave energy radiated from the cavity is

$$
\begin{aligned}
Q_{2 \ell} & =q_{o l} A_{1} F_{12}=q_{o l} A_{2} \\
& =\frac{\varepsilon_{\ell} A_{2} \sigma T^{4}}{1-\left(1-\varepsilon_{\ell}\right) F_{11}}
\end{aligned}
$$

Short wave energy reflected out of the cavity is 
1

$$
\begin{aligned}
Q_{2 s} & =q_{O s} A_{1} F_{12} \\
& =Q_{s o 1} F_{12} \frac{1-\varepsilon_{s}}{1-\left(1-\varepsilon_{s}\right) F_{11}} .
\end{aligned}
$$

For the O.G. receiver,

$$
A_{2} / A_{1}=0.036
$$

Using this value and property values from Sec. A.l gives

$$
\begin{aligned}
& Q_{2 \ell}=0.99 \mathrm{~A}_{2} \sigma \mathrm{T}^{4} \\
& Q_{2 s}=0.005 \mathrm{Q}_{\text {sol }} .
\end{aligned}
$$

Therefore, the $0 . G$. cavity essentially radiates as a blackbody with area $A_{2}$ and it reflects $0.5 \%$ of the solar energy input.

\section{A.4 SAMPLE PERFORMANCE CALCULATION: 1500 PSIA, 1100 F STEAM}

The general procedure suggested in the main text is followed.

\section{A.4.1 Net Optical Energy Input}

Following Bohn (1979), let $\mathrm{q}_{\mathrm{o}}=34,000 \mathrm{Btu} / \mathrm{h}$. This reflects the relatively poor optical performance of the concentrator.

\section{A.4.2 Therma.1 Toss}

Use Eq. 2-13 with $\mathrm{T}_{\mathrm{R}}=1100 \mathrm{~F}=593 \mathrm{C}$ and $\mathrm{T}_{\infty}=60 \mathrm{~F}=16 \mathrm{C}$; if $\mathrm{U}=1.9 \mathrm{~m} / \mathrm{s}$,

$$
\mathrm{q}_{\mathrm{rec}}=3870 \mathrm{Btu} / \mathrm{h}
$$

\section{A.4:3 Fluid Enthalpy Rise}

$$
\dot{\mathrm{m}} \Delta \mathrm{H}=\mathrm{q}_{\mathrm{o}}-\mathrm{q}_{\mathrm{rec}}=30,130 \mathrm{Btu} / \mathrm{h} \text {. }
$$

Assume an inlet water temperature of $200 \mathrm{~F}$. Data from steam tables give

$$
\dot{\mathrm{m}}=21.831 \mathrm{bm} / \mathrm{h}
$$


From Eqs. 3-1 and 3-2,

$$
\Delta T_{f}=\frac{h \pi d_{i}}{\dot{m} c_{p}}\left(T_{R}-T_{f}\right) d x
$$

Calculate $h$ from the Colburn relationship [11]:

$$
\begin{aligned}
\frac{h d_{i}}{k} & =0.023 \operatorname{Re}^{U .8} \operatorname{Pr}^{1 / 3}, \\
\operatorname{Re} & =4 \dot{m} / \pi \mu d_{i} .
\end{aligned}
$$

Given properties of a water/steam working fluid from $200 \mathrm{~F}$ at 1500 psia (Kaminski 1977; Keenan et al. 1969), choose $\Delta \mathrm{T}_{\mathrm{f}}$ steps of $100 \mathrm{~F}$ for which the fluid properties are reasonably constant. Starting at the inlet, step through, calculating $\mathrm{dx}$ required for each $100 \mathrm{~F}$ increase in water temperature, using fluid properties that are an average over that range, until saturation is reached. The conditions, values, and results are shown in Table A-l.

Table A-1. HEAT TRANSFER TO WORRING FLUID: INLET TO SATURA'IIUN

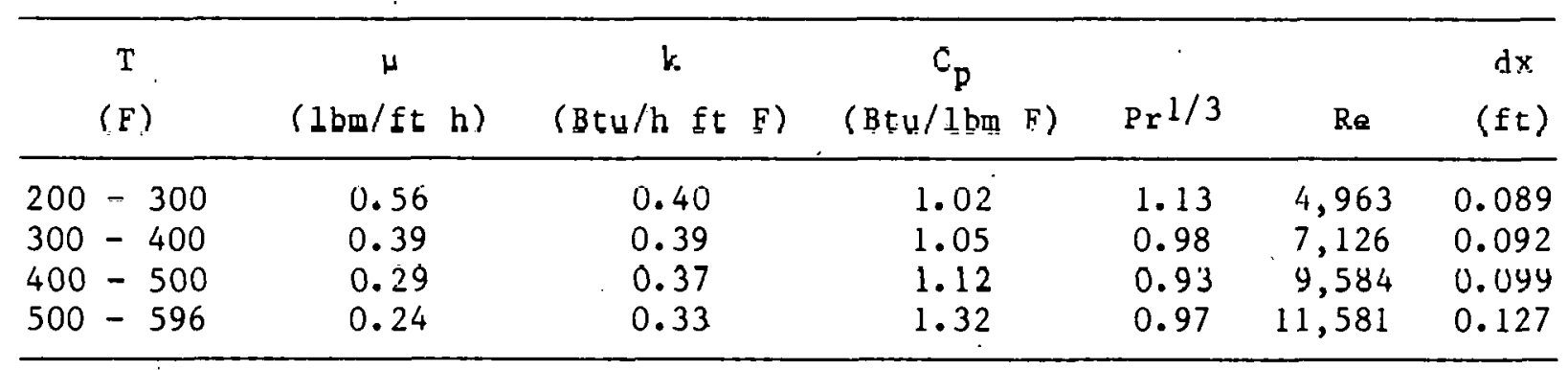

Thus, a tube length of $4.88 \mathrm{in}$. is required to bring the water to saturation.

The length of tube required to boil the water is

$$
L_{\text {boil }}=\frac{\mathrm{H}_{f g}}{\pi d_{i} h_{\text {boil }}\left(T-T_{\text {sat }}\right)} \quad \therefore
$$

Determination of the average heat transfer coefficient $h_{\text {boil }}$ during boiling is the only difficulty in finding $\mathrm{L}_{\text {boil }}$. The method used here is to calculate 
the burnout heat transfer coefficient from the Griffith correlation and the quality at which burnout occurs from the method of Davis and David (1964). The heat transfer coefficient is assumed to increase linearly with quality from the saturated liquid value to the burnout value and then to decrease linearly to the saturated vapor value. An average value then may be computed. Typically, these values of $h_{\text {boil }}$ are about $200 \mathrm{n} \cdot \mathrm{Btu} / \mathrm{h} \mathrm{ft}^{2} \mathrm{~F}$, giving

$$
\mathrm{L}_{\text {boil }}=9.2 \mathrm{in} \text {. }
$$

Note that the tube length required to bring the inlet water to saturated vapor is $14 \mathrm{in.}$, which is much less than the total tube length of $96 \mathrm{in.}$ Therefore, errors in calculating $h_{\text {boil }}$ will have a very small effect on the calculated outlet steam temperature.

Continuing from the saturated vapor state, the values given in Table A-2 are obtained.

Table A-2. HEAT TRANSFER TO WORRING FLUID: SATURATION TO OUTLET

\begin{tabular}{ccccccc}
\hline $\mathrm{T}$ & $\mu$ & $\mathrm{k}$ & $\mathrm{C}_{\mathrm{p}}$ & $\mathrm{Pr}^{1 / 3}$ & $\operatorname{Re} / 10^{3}$ & $\mathrm{dx}$ \\
\hline $596-700$ & 0.061 & 0.045 & 1.30 & 1.18 & 45.6 & 0.308 \\
$700-800$ & 0.064 & 0.042 & 0.77 & 1.05 & 43.4 & 0.294 \\
$800-900$ & 0.066 & 0.043 & 0.67 & 1.01 & 42.1 & 0.372 \\
$900-1000$ & 0.071 & 0.046 & 0.62 & 0.99 & 39.1 & 0.581 \\
$1000-$ & 0.077 & 0.050 & 0.60 & 0.97 & 36.1 & 5.278 \\
\hline
\end{tabular}

The last step is to calculate the steam temperature change over the remaining tube length $(5.278 \mathrm{ft})$. Since the temperature increase over this section is limited to $100 \mathrm{~F}$, we assume properties evaluted at $1050 \mathrm{~F}$ as in Table A-2. This calculation gives

$$
\mathrm{T}_{\mathrm{R}}-\left.\mathrm{T}_{\mathrm{f}}\right|_{\text {outlet }}=\mathrm{T}_{\mathrm{R}}-\left.\mathrm{T}_{\mathrm{f}}\right|_{\text {inlet }} \exp \left[-(\mathrm{dx}) \mathrm{h}_{\mathrm{d}} \mathrm{i}_{\mathrm{i}} / \dot{\mathrm{m}}_{\mathrm{p}}\right] \text {. }
$$

For this sertion $T_{R}-\left.T_{F}\right|_{\text {inlet }}=100 \mathrm{~F}$ giving

$$
\mathrm{T}_{\mathrm{R}}-\mathrm{T}_{\mathrm{f}} \mathrm{l}_{\text {outlet }}=0.2 \mathrm{~F} \text {. }
$$

Therefore, the steam outlet temperature is essentially the receiver temperature, $1100 \mathrm{~F}$. 


\begin{tabular}{|c|c|c|}
\hline \begin{tabular}{c|c}
$\begin{array}{c}\text { Document Control } \\
\text { Page }\end{array}$ & $\begin{array}{c}\text { 1. SERI Report No. } \\
\text { TR }-631-387\end{array}$ \\
\end{tabular} & 2. NTIS Accession No. & 3. Recipient's Accession No. \\
\hline 4. Title and Subtitle & & $\begin{array}{l}\text { 5. Publication Date } \\
\text { March } 1980\end{array}$ \\
\hline \multicolumn{2}{|l|}{ Analysis of The Omnium-G Receiver } & 6. \\
\hline \multicolumn{2}{|l|}{$\begin{array}{l}\text { 7. Author(s) } \\
\text { Mark Bohn }\end{array}$} & 8. Periorming Organization Rept. No. \\
\hline \multirow{2}{*}{\multicolumn{2}{|c|}{$\begin{array}{l}\text { 9. Pertorming Organization Name and Address } \\
\text { Solar Energy Research Institute } \\
1617 \text { Cole Boulevard } \\
\text { Golden, Colorado }\end{array}$}} & $\begin{array}{l}\text { 10. ProjectTask/Work Unit No. } \\
3457.11\end{array}$ \\
\hline & & $\begin{array}{l}\text { 11. Contract (C) or Grant (G) No. } \\
\text { (C) } \\
\text { (G) }\end{array}$ \\
\hline \multirow[t]{2}{*}{ 12. Sponsoring Organization Name and Address } & \multirow[t]{2}{*}{ · } & $\begin{array}{c}\text { 13. Type of Report \& Period Covered } \\
\text { Technical Report }\end{array}$ \\
\hline & & \begin{tabular}{|l}
14. \\
\end{tabular} \\
\hline
\end{tabular}

15. Supplementary Notes

16. Abstract (Limit: 200 words)

A thermal analysis of the Omnium-G receiver is presented and the analysis technique is shown to be applicable to a general class of solar thermal receivers--those utilizing a thermal mass. The thermal loss coefficient, including reradiation losses, is calculated and shown to agree quite well with the experimentally measured thermal loss coefficient.

Heat transfer to the working fluid is also analyzed and the analysis is then used to show that the Omnium-G receiver is well matched to the water/steam working fluid, i.e., that the steam outlet temperature is almost the same as the receiver temperature.

A general procedure for calculating receiver performance is then presented. This will allow one to compute the energy delivery to any working fluid, the delivered temperature of the working fluid, and the pressure drop through the receiver. An example of the calculation. is presented.

17. Document Analysis

a. Descriptors Central Receivers; Heat Losses; Thermal Analysis; Performance Testing;

Performance; Thermal Loss Coefficient; Hedi Transfer; Heat Transfer

Fluids

b. Identifiers/Open-Ended Terms

c. UC Categories

62

18. Availability Statement

National Technical Information Service

U.S. Department of Commerce

5285 Port Royal Road

Springfield, Virginia 22161 